\title{
Serum periostin does not reflect type 2- driven inflammation in COPD
}

\author{
O. A. Carpaij, ${ }^{1,2}$, F. O. W. Muntinghe ${ }^{2}$, M. B. Wagenaar ${ }^{2}$, J. W. Habing ${ }^{2}$, W. Timens ${ }^{1,3}$, H. A. M. Kerstjens ${ }^{1,2}$, \\ M. C. Nawijn 1,3, L. I. Z. Kunz ${ }^{4}$, P. S. Hiemstra ${ }^{4}$, G. W. Tew ${ }^{5}$, C. T. J. Holweg ${ }^{5}$, C. A. Brandsma 1,3 \\ and $M$. van den Berge ${ }^{1,2}$
}

\begin{abstract}
Although Th2 driven inflammation is present in COPD, it is not clearly elucidated which COPD patients are affected. Since periostin is associated with Th2 driven inflammation and inhaled corticosteroid (ICS)-response in asthma, it could function as a biomarker in COPD. The aim of this study was to analyze if serum periostin is elevated in COPD compared to healthy controls, if it is affected by smoking status, if it is linked to inflammatory cell counts in blood, sputum and endobronchial biopsies, and if periostin can predict ICS-response in COPD patients.

Serum periostin levels were measured using Elecsys Periostin immunoassay. Correlations between periostin and inflammatory cell count in blood, sputum and endobronchial biopsies were analyzed. Additionally, the correlation between serum periostin levels and treatment responsiveness after 6 and 30 months was assessed using i.e. $\Delta$ FEV $1 \%$ predicted, $\triangle \mathrm{CCQ}$ score and $\triangle \mathrm{RV} / \mathrm{TLC}$ ratio. Forty-five COPD smokers, 25 COPD past-smokers, 22 healthy smokers and 23 healthy never-smokers were included. Linear regression analysis of serum periostin showed positive correlations age ( $B=0.02,95 \% \mathrm{Cl} 0.01-0.03)$ and $F E V 1 \%$ predicted $(B=0.01,95 \% \mathrm{Cl} 0.01-0.02)$ in healthy smokers, but not in COPD patients In conclusion, COPD -smokers and -past-smokers have significantly higher periostin levels compared to healthy smokers, yet periostin is not suitable as a biomarker for Th2-driven inflammation or ICSresponsiveness in COPD.
\end{abstract}

Keywords: Serum periostin, COPD, Biomarker, Type 2-inflammation, Inhaled corticosteroid response

\section{To the editor}

Recent research suggests that type 2-driven eosinophilic inflammation is present in a subset of COPD patients [1]. This is important as it may predict responsiveness to anti-inflammatory treatment with inhaled corticosteroids (ICS) and possibly also targeted therapies like interleukin-5 monoclonal antibodies [2].

Periostin is an extracellular matrix protein that has been proposed as biomarker for type 2-driven inflammation [3]. While the majority of studies so far investigated the clinical implication of circulating periostin levels in asthma, data regarding COPD is scarce [3-5].

\footnotetext{
* Correspondence: o.a.carpaij@umcg.nl

${ }^{1}$ University of Groningen, University Medical Center Groningen, Groningen Research Institute for Asthma and COPD (GRIAC), Groningen, The Netherlands

2Department of Pulmonology, University of Groningen, University Medical Center Groningen, Hanzeplein 1, 9713, GZ, Groningen, The Netherlands Full list of author information is available at the end of the article
}

The aim of this study was to investigate whether serum periostin levels are different in COPD patients compared to healthy controls and whether they are affected by smoking. In addition, we assessed to what extent serum periostin levels reflect inflammatory cell counts in blood, sputum and endobronchial biopsies in COPD and whether serum periostin levels predict airway wall remodeling and ICS responsiveness following treatment of 6 or 30 months.

We included COPD patients who participated in the Groningen and Leiden Universities study of Corticosteroids in Obstructive Lung Disease (GLUCOLD) as described previously [6, 7]. Patients were 45-75 years, Caucasian, had an $\mathrm{FEV}_{1} / \mathrm{FVC}$ ratio $<70 \%, \geq 10$ pack years, and no history of asthma. Subjects were randomly assigned to receive long-term ICS with or without an added long-acting beta2-agonist (LABA) or placebo-treatment. 
Healthy subjects were 40-75 years, Caucasian, had an $\mathrm{FEV}_{1} / \mathrm{FVC}$ ratio $\geq 70 \%$ and $\mathrm{PC}_{20}$ methacholine > $19.6 \mathrm{mg} / \mathrm{mL}$ [8], and were divided into smokers (i.e. smoking $\geq 10$ cigarettes/day and $\geq 10$ pack years) and never-smokers.

From the previous studies [6, 8], COPD patients and healthy controls underwent the following tests: pulmonary function tests, peripheral blood tests, sputum induction, a bronchoscopy and filled in questionnaires. From the present study, serum periostin levels were measured using the clinical trial version of the Elecsys ${ }^{\oplus}$ Periostin immunoassay (Roche Diagnostics, Penzberg Germany) [9].

The local ethics committee approved both study protocols and all subjects gave written informed consent.

First, demographic and clinical variables in COPD patients and healthy controls were compared using independent sample t-tests for normally distributed data, Mann-Whitney U tests for non-normally distributed data and chi-square tests for categorical variables. To assess possible confounders of $\log 2$ transformed periostin values, a univariate analysis was performed. Next, a linear regression model was used to assess the association between serum periostin levels and inflammatory cell counts in blood, sputum and endobronchial biopsies at baseline, with correction for significant confounders. A linear regression was used to analyze serum periostin levels in association with ICS treatment responsiveness (i.e. change in $\mathrm{FEV}_{1}$, Clinical COPD Questionnaire (CCQ)-total score and RV/TLC after 6 and 30 months treatment) and airway wall remodelling in COPD patients. Airway wall remodeling in endobronchial biopsies was measured by dividing immunohistochemical stained area for elastic fibers, versican, decorin, collagen I and III by the total selected lamina propria area as described previously [7].

Of the 114 COPD patients enrolled in GLUCOLD, 70 subjects had available measured serum periostin level at baseline. COPD smokers $(n=45 / 70)$ were 60.3 (SD \pm 7.9) years, smoked $46.7(\mathrm{SD} \pm 19.8)$ packyears, had a $\%$ $\mathrm{FEV}_{1}$ predicted of $63.8 \%(\mathrm{SD} \pm 7.8 \%)$ and a serum periostin level of $51.8 \mathrm{ng} / \mathrm{ml}$ [IQR $48.4-59.8 \mathrm{ng} / \mathrm{ml}$ ]. COPD former-smokers $(n=25 / 70)$ had a mean age of 64.7 (SD \pm 7.3 ), smoked $45.6(\mathrm{SD} \pm 27.7)$ pack years, $\% \mathrm{FEV}_{1}$ predicted of $60.9 \%(\mathrm{SD} \pm 10.5 \%)$ and a serum periostin level of $54.8 \mathrm{ng} / \mathrm{ml}$ [IQR 47.8-62.2 ng/ml]. The healthy smokers $(n=22)$ were $52.1(\mathrm{SD} \pm 7.5)$ years, smoked 29.0 $(\mathrm{SD} \pm 11.6)$ pack years, had a mean $\% \mathrm{FEV}_{1}$ predicted of $104.0 \%(\mathrm{SD} \pm 11.2 \%)$ and a serum periostin of $44.6 \mathrm{ng} /$ $\mathrm{ml}$ [IQR 39.8-51.2 ng/ml]. The healthy never-smokers $(n=23)$ had a mean age of $58.4(\mathrm{SD} \pm 9.1)$, mean $\mathrm{FEV}_{1} \%$ predicted of $108.6 \%$ (SD $\pm 13.9 \%)$ and serum periostin of $49.7 \mathrm{ng} / \mathrm{ml}$ [IQR $41.8-54.7 \mathrm{ng} / \mathrm{ml}$ ] (see Additional file 1).

Serum periostin was significantly higher in COPD smokers $(P=0.009)$ as well as COPD former-smokers
$(P=0.001)$ compared to the healthy smoker-group. Serum periostin was similar between COPD smokers and COPD former-smokers. In agreement with our findings, Golpe et al. also found higher significantly periostin levels in both tobacco smoke- as well as biomass cooking-induced COPD compared to healthy controls [10]. However, the latter study only investigated never-smoking controls and did not include matched current- and former-smoking controls. In addition, they used another method to analyse serum periostin and found undetectable levels in the never-smoking controls. Two other studies did not find a difference in serum periostin levels between COPD and predominantly never-smoker controls [4, 5].

In our study, healthy never-smokers tended to have higher periostin levels compared to healthy smokers $(P$ $=0.08$ ), which was also seen in other studies $[11,12]$. Caswell-Smith et al. saw a significantly higher periostin level in 312 never-smokers compared to 22 healthy smokers [12]. Taking together, there is evidence that current smoking is associated with lower serum periostin levels in healthy controls. It is interesting to note that studies from our laboratories using cultured human bronchial epithelial cells did not provide evidence for induction of epithelial periostin expression by cigarette smoke exposure, an even showed that type 2 cytokine (IL-13) induced periostin expression was suppressed by cigarette smoke [13].

Next, we assessed the correlations between serum periostin levels and clinical and inflammatory characteristics in COPD patients and healthy smokers and never-smokers. Results of the univariate and linear regression analyses are presented in Table 1. In COPD patients, no correlation was found between periostin and age, lung function and inflammatory cell counts in blood, sputum and biopsies. In the healthy smoker-group, periostin levels were significantly positively associated with age $(\mathrm{B}=0.02,95 \% \mathrm{CI} 0.01-0.03)$ and post-bronchodilator $\mathrm{FEV}_{1} \%$ predicted $(\mathrm{B}=0.01,95 \% \mathrm{CI}$ 0.01-0.02). After adjusting the data for the last mentioned possible confounders, no further correlations were found in the healthy smokers. In the healthy never-smoker group, periostin was associated with higher percentages of sputum lymphocytes $(\mathrm{B}=0.3$, 95\%CI $0.1-0.5)$. Our finding is that serum periostin levels do not reflect type 2-driven inflammation in COPD, is in agreement with the findings of Konstantelou et al. who measured serum periostin in 155 COPD patients admitted for a COPD exacerbation and found no correlations with severity of airflow obstruction or eosinophilic inflammation measured in blood [14].

To our analysis, baseline periostin levels did not predict ICS responsiveness in COPD; there was no correlation with improvement in lung function, decrease in hyperinflation or CCQ-total score after either 6 or 30 months of ICS-treatment. Studies investigating periostin as 
Table 1 Regression analysis of baseline log2 transformed periostin with baseline characteristics in COPD-patients, healthy smokers and never-smokers

\begin{tabular}{|c|c|c|c|}
\hline & $\begin{array}{l}\text { ICS naive COPD } \\
(n=70)\end{array}$ & $\begin{array}{l}\text { Healthy smoker } \\
(n=22)\end{array}$ & $\begin{array}{l}\text { Healthy never-smoker } \\
(n=23)\end{array}$ \\
\hline Univariate regression & $B_{\exp }(95 \% \mathrm{Cl})$ & $\mathrm{B}_{\exp }(95 \% \mathrm{Cl})$ & $B_{\exp }(95 \% \mathrm{Cl})$ \\
\hline Sex, male (\%) & $4.7(0.6-36.9)$ & $0.2(0.004-11.4)$ & $1.9(0.1-29.7)$ \\
\hline Smokers (\%) & $0.4(0.1-2.0)$ & NA & NA \\
\hline Linear regression & B $(95 \% \mathrm{Cl})$ & B $(95 \% \mathrm{Cl})$ & B $(95 \% \mathrm{Cl})$ \\
\hline Packyears (years) & $7.0 \times 10^{-5}(-0.004-0.004)$ & NA & NA \\
\hline Age (years) & $0.01(-0.003-0.2)$ & $0.02(0.01-0.03) *$ & $0.01(-0.01-0.03)$ \\
\hline $\mathrm{BMl},\left(\mathrm{kg} / \mathrm{m}^{2}\right)$ & $0.2(-0.1-0.1)$ & $-0.1(-0.3-0.1)$ & $0.04(-0.1-0.2)$ \\
\hline$\%$ predicted $\mathrm{FEV}_{1}$ post-bronchodilator & $-0.03(-0.01-0.01)$ & $0.01(0.04-0.02) *$ & $0.01(-0.01-0.02)$ \\
\hline $\mathrm{FEV}_{1} / \mathrm{IVC}$ ratio (\%) & $0.01(-0.004-0.01)$ & $0.0(-0.02-0.02)$ & $0.013(-0.02-0.04)$ \\
\hline RV/TLC ratio (\%) & $0.003(-0.01-0.01)$ & $0.02(-0.02-0.1)$ & $0.02(-0.01-0.04)$ \\
\hline Fractional exhaled Nitric Oxide (ppb) & $0.001(-0.01-0.01)$ & NA & NA \\
\hline Total lgE (IU/L) & $4.2 \times 10^{-5}(0.0-0.0)$ & NA & NA \\
\hline $\mathrm{PC}_{20}$ methacholin threshold $(\mathrm{mg} / \mathrm{ml}){ }^{\#}$ & $0.1(-0.03-0.1)$ & NA & NA \\
\hline Blood eosinophils (\%) ${ }^{\#}$ & $0.1(-0.03-0.1)$ & $-0.07(-0.2-0.1)$ & $0.03(-0.2-0.2)$ \\
\hline Blood basophils (\%) ${ }^{\#}$ & $0.04(-0.04-0.1)$ & $-0.1(-0.2-0.1)$ & $0.1(-0.1-0.2)$ \\
\hline Blood neutrophils (\%) & $-0.001(-0.01-0.01)$ & $-0.004(-0.02-0.01)$ & $-0.02(-0.04-0.01)$ \\
\hline Blood monocytes (\%) & $0.03(-0.01-0.1)$ & $0.01(-0.1-0.1)$ & $0.02(-0.08-0.1)$ \\
\hline Blood lymphocytes (\%) & $-0.003(-0.01-0.01)$ & $0.01(-0.01-0.02)$ & $0.02(-0.01-0.04)$ \\
\hline Sputum eosinophils (\%) & $-0.01(-0.1-0.04)$ & $-0.01(-0.2-0.1)$ & $0.1(-0.1-0.2)$ \\
\hline Sputum neutrophils (\%) & $-7.7 \times 10^{-6}(-0.01-0.01)$ & $0.002(-0.006-0.01)$ & $-0.004(-0.01-0.01)$ \\
\hline Sputum macrophages (\%) & $-0.001(-0.01-0.01)$ & $-0.002(-0.01-0.01)$ & $0.001(-0.01-0.01)$ \\
\hline Sputum lymphocytes (\%) & $0.1(-0.01-0.1)$ & $0.108(-0.2-0.4)$ & $0.3(0.1-0.5) *$ \\
\hline Biopsy eosinophils (count/0.1 mm²) & $-0.001(-0.003-0.002)$ & $-0.03(-0.1-0.06)$ & $0.01(-0.03-0.04)$ \\
\hline Biopsy neutrophils (count/0.1 mm²) \# & $0.02(-0.03-0.08)$ & $-0.002(-0.07-0.07)$ & $-0.08(-0.2-0.04)$ \\
\hline Biopsy macrophages (count/0.1 mm²) \# & $0.045(-0.03-0.1)$ & $-0.03(-0.1-0.1)$ & $0.03(-0.1-0.1)$ \\
\hline Biopsy lymphocytes (count/0.1 mm²) & $0.000(-0.001-0.001)$ & $-0.01(-0.01-0.002)$ & $-0.02(-0.1-0.1)$ \\
\hline Biopsy elastic fibers area (\%) & $0.002(-0.01-0.01)$ & NA & NA \\
\hline Biopsy elastic fibers density (gray value) & $0.002(-0.01-0.02)$ & NA & NA \\
\hline Biopsy versican area (\%) & $-0.001(-0.01-0.01)$ & NA & NA \\
\hline Biopsy versican density (gray value) & $-0.01(-0.03-0.01)$ & NA & NA \\
\hline Biopsy decorin area (\%) & $-8.15 \times 10^{-6}(<0.001-<0.001)$ & NA & NA \\
\hline Biopsy decorin density (gray value) & $-0.003(-0.1-0.045)$ & NA & NA \\
\hline Biopsy collagen I area (\%) & $-0.003(-0.01-0.01)$ & NA & NA \\
\hline Biopsy collagen I density (gray value) & $0.003(-0.02-0.03)$ & NA & NA \\
\hline Biopsy collagen III area (\%) & $-0.004(-0.01-0.03)$ & NA & NA \\
\hline Biopsy collagen III density (gray value) & $-0.01(-0.02-0.01)$ & NA & NA \\
\hline Biopsy mean number of ki-67 pos. Cells (count/ $0.1 \mathrm{~mm}^{2}$ ) & $0.001(-0.001-0.003)$ & NA & NA \\
\hline Biopsy PAS pos. Area epithelium (\%) & $0.000(-0.01-0.01)$ & NA & NA \\
\hline Biopsy EGFR pos. Epithelium area (\%) & $0.002(-0.01-0.01)$ & NA & NA \\
\hline Biopsy EGFR pos. Epithelium density (gray value) & $5.8 \times 10^{-6}(<0.001-<0.001)$ & NA & NA \\
\hline
\end{tabular}

\#: log2 transformed variable, ${ }^{*}$ : statistically significant $P<0.05, B M I:$ Body Mass Index. NA: not available, area (\%): the percentage stained area for a specific extracellular matrix component was calculated dividing the stained area by the total selected area, density (gray value): staining intensity was analyzed by densitometry (weighted mean per biopsy) and presented as gray value (black: gray value: 0 , white: gray value: 255 ) 
biomarker for ICS treatment in COPD patients are limited. In this context, the findings of Park et al. are of interest [15]. They studied 130 COPD patients before and after three months of ICS/LABA treatment and found that a combination of high plasma periostin levels $(>23 \mathrm{ng} / \mathrm{mL}$ ) and high blood eosinophil counts $(>260 / \mu \mathrm{L})$ could predict a better improvement in $\mathrm{FEV}_{1}$. However, it is important to note that patients with this combination of high periostin and blood eosinophils already had a higher bronchodilator response at baseline and therefore the better improvement might have been due to the LABA component alone.

Finally, no correlation was detected between baseline periostin and change in extracellular matrix (lamina propria components stained area or density) after 30 months on ICS or placebo treated COPD patients (see Additional file 1).

\section{Conclusion}

In conclusion, we show that smoking and former-smoking COPD patients have significantly higher serum periostin values compared to healthy smoking controls, yet periostin levels do not reflect type 2-driven inflammation, airway remodeling, or ICS treatment responsiveness and is thus not a good biomarker in this population.

\section{Additional file}

Additional file 1: Supplementary Tables. (DOCX $95 \mathrm{~kb})$

\section{Abbreviations}

CCQ: Clinical COPD Questionnaire; GLUCOLD: Groningen and Leiden Universities study of Corticosteroids in Obstructive Lung Disease; ICS: Inhaled corticosteroids; LABA: Long-acting beta2-agonist

\section{Availability of data and materials}

The data that support the findings of this study are available from Genentech but restrictions apply to the availability of these data, which were used under license for the current study, and so are not publicly available. Data are however available from the authors upon reasonable request and with permission of Genentech.

\section{Declarations}

- O.A. Carpaij OA, F.O.W. Muntinghe, M.B. Wagenaar, J.W. Habing, M.C. Nawijn, L.I.Z. Kunz and C.A. Brandsma report no relationship/ conditions/circumstances that present a potential conflict of interest.

- W. Timens reports personal fees from Pfizer, personal fees from GSK, personal fees from Chiesi, personal fees from Roche, Diagnostics / Ventana, grants from Dutch Asthma Fund, personal fees from Biotest, personal fees from Merck Sharp Dohme, personal fees from Novartis, personal fees from Lilly Oncology, personal fees from Boehringer Ingelheim, personal fees from Astra-Zeneca, personal fees from Bristol-Myers-Squibb, outside the submitted work.

- H.A.M. Kerstjens reports that his institution has received fees per patient for recruitment in trials from GSK, NOVARTIS, and FLUIDDA, grants for investigator initiated studies from GSK, NOVARTIS, and Boerhinger. Additionally, his institution has received consultancy fees from Novartis, AstraZeneca, Boehringer Ingelheim, GlaxoSmithKline.

- P.S. Hiemstra reports grants from Boehringer Ingelheim, grants from Galapagos N.V., outside the submitted work.

- G.W. Tew reports other from Genentech Inc., during the conduct of the study.
- C.T.J. Holweg reports that she is an employee of Genentech Inc., a Member of the Roche Group.

- M. van den Berge reports grants paid to University from GlaxoSmithKline, Chiesi, Teva, Astra-Zeneca, Genentech, outside the submitted work.

\section{Authors' contributions}

OAC, FOWM, MBW, JWH, LIZK and MvdB analyzed, interpreted the patients data and periostin levels. $O A C$ and $M v d B$ were involved in drafting the manuscript. WT, HAMK, CTJH, GT, CAB, MCN and PSH were involved in conception and design of the data, interpretation of the data and contributed in writing the manuscript. All authors read and approved the final manuscript.

\section{Ethics approval and consent to participate}

The local ethics committee (METc University Medical Center Groningen) approved both study protocols and all subjects gave written informed consent.

\section{Competing interests}

The authors declare that they have no competing interests.

\section{Publisher's Note}

Springer Nature remains neutral with regard to jurisdictional claims in published maps and institutional affiliations.

\section{Author details}

${ }^{1}$ University of Groningen, University Medical Center Groningen, Groningen Research Institute for Asthma and COPD (GRIAC), Groningen, The Netherlands. ${ }^{2}$ Department of Pulmonology, University of Groningen, University Medical Center Groningen, Hanzeplein 1, 9713, GZ, Groningen, The Netherlands. ${ }^{3}$ Department of Pathology and Medical Biology, University of Groningen, University Medical Center Groningen, Groningen, The Netherlands. ${ }^{4}$ Department of Pulmonology, Leiden University Medical Center, Leiden, The Netherlands. ${ }^{5}$ Genentech, Inc., OMNI Biomarker Development, South San Francisco, California, USA.

Received: 25 April 2018 Accepted: 30 May 2018

Published online: 07 June 2018

\section{References}

1. George L, Brightling CE. Eosinophilic airway inflammation: role in asthma and chronic obstructive pulmonary disease. Ther Adv Chronic Dis. 2016;7:34-51

2. Pavord ID, Chanez P, Criner GJ, et al. Mepolizumab for Eosinophilic chronic obstructive pulmonary disease. N Engl J Med. 2017;377:1613-29.

3. Izuhara K, Conway SJ, Moore BB, et al. Roles of Periostin in respiratory disorders. Am J Respir Crit Care Med. 2016;193:949-56.

4. Han S-S, Lee WH, Hong Y, et al. Comparison of serum biomarkers between patients with asthma and with chronic obstructive pulmonary disease. J Asthma. 2016;53:583-8.

5. Górska K, Maskey-Warzęchowska M, Nejman-Gryz P, et al. Comparative study of periostin expression in different respiratory samples in patients with asthma and chronic obstructive pulmonary disease. Pol Arch Med Wewn. 2016;126:124-37.

6. Lapperre TS, Snoeck-Stroband JB, Gosman MME, et al. Effect of fluticasone with and without salmeterol on pulmonary outcomes in chronic obstructive pulmonary disease: a randomized trial. Ann Intern Med. 2009;151:517-27.

7. Kunz LIZ, Strebus J, Budulac SE, et al. Inhaled steroids modulate extracellular matrix composition in bronchial biopsies of COPD patients: a randomized, controlled trial. PLoS One. 2013;8:e63430.

8. Telenga ED, Oudkerk M, van Ooijen PMA, et al. Airway wall thickness on HRCT scans decreases with age and increases with smoking. BMC Pulm Med. 2017;17:27.

9. Palme $\mathrm{S}$, Christenson RH, Jortani SA, et al. Multicenter evaluation of analytical characteristics of the Elecsys $\left({ }^{\oplus}\right)$ Periostin immunoassay. Clin Biochem. 2017:50:139-44.

10. Golpe R, Martín-Robles I, Sanjuán-López P, et al. Differences in systemic inflammation between cigarette and biomass smoke-induced COPD. Int J Chron Obstruct Pulmon Dis. 2017;12:2639-46. 
11. Thomson NC, Chaudhuri R, Spears M, et al. Serum periostin in smokers and never smokers with asthma. Respir Med. 2015;109:708-15.

12. Caswell-Smith R, Hosking A, Cripps T, et al. Reference ranges for serum periostin in a population without asthma or chronic obstructive pulmonary disease. Clin Exp Allergy. 2016;46:1303-14.

13. Mertens TCJ, van der Does AM, Kistemaker LE, et al. Cigarette smoke differentially affects IL-13-induced gene expression in human airway epithelial cells. Physiol Rep. 2017;5:e13347.

14. Konstantelou E, Papaioannou Al, Loukides S, et al. Serum periostin in patients hospitalized for COPD exacerbations. Cytokine. 2017;93:51-6.

15. Park HY, Lee $H$, Koh W-J, et al. Association of blood eosinophils and plasma periostin with FEV1 response after 3-month inhaled corticosteroid and longacting beta2-agonist treatment in stable COPD patients. Int I Chron Obstruct Pulmon Dis. 2016;11:23-30

Ready to submit your research? Choose BMC and benefit from:

- fast, convenient online submission

- thorough peer review by experienced researchers in your field

- rapid publication on acceptance

- support for research data, including large and complex data types

- gold Open Access which fosters wider collaboration and increased citations

- maximum visibility for your research: over $100 \mathrm{M}$ website views per year

At BMC, research is always in progress.

Learn more biomedcentral.com/submissions 